\title{
El concepto de Zonas de Influencia y su aplicación en las relaciones entre Argentina y Chile
}

\author{
Pablo Lacoste
}

La categoría de Zona de Influencia ha sido recurrentemente utilizada por Raymond Aron para explicar el fincionamiento del sistema internacional durante las tensiones de la Guerra Fría. Para el citado autor, este mecanismo, apoyado en el enfoque realista de las Relaciones Internacionales, contribuyó a mantener cierta estabilidad en el sistema, y evitó la guerra caliente entre las super-potencias. El presente trabajo examina críticamente estas categorias y trata de resignificarlas para su empleo en el escenario regional, especialmente para tratar de comprender con mayor claridad la evolución de las relaciones entre Argentina y Chile que, a pesar de haber alcanzado momentos de tensión diplomática y militar, finalmente lograron superar estas dificultades y la paz se mantuvo inalterable. Hubo tensiones, recelos y competencia entre ambas, pero nunca se llegó a la guerra caliente. Ello fue el resultado del empleo del enfoque realista de la Teoría de las Relaciones Internacionales por parte de las cancillerias de ambos países, como así también de la acción de las superpotencias, que en los momentos decisivos, presionaron a ambas cancillerias para mantener la paz en el área.

Si bien la teoría de las Relaciones Internacionales ha sido desarrollada fundamentalmente en y para las Grandes Potencias, resulta conveniente examinar las categorías teóricas de esta disciplina a los efectos de generar las herramientas que permitan describir, explicar y predecir la acción de los países periféricos en el escenario internacional.

Esto sucede claramente en el caso del concepto de Zonas de Influencia, diseñado para dar cuenta de actores cuya capacidad de acción militar, política, económica y cultural es muy superior a la de los países latinoamericanos en general, y Argentina y Chile en particular. Pero el análisis de esta categoría puede ser un buen punto de partida para el abordaje de los problemas regionales de países periféricos, siempre y cuando se efectúe la necesaria resignificación del concepto original para adaptarlo a la realidad de Estados con capacidad de acción regional pero no mundial.

El presente trabajo está dividido en dos partes. En la primera examinamos el desarrollo del teórico francés Raymond Aron sobre el concepto de Zonas de Influencia. Tratamos de observar las principales caracte- 
rísticas de este término y la forma de utilizarlo en distintos escenarios internacionales y regionales. En la segunda parte aplicamos el concepto teórico de Zonas de Influencia en el caso particular de las relaciones entre Argentina y Chile. Intentamos descubrir la inteligibilidad de los procesos muchas veces confusos de las relaciones internacionales en la región, mediante la aplicación de esta herramienta teórica. Finalmente, arriesgamos una serie de conclusiones con recomendaciones concretas para el diseño de las políticas exteriores de ambos países.

\section{Zonas de Influencia: definiciones teóricas}

La Zona de Influencia es un modelo de análisis que permite dar cuenta de un sistema internacional, formado al menos por cuatro actores: dos relativamente fuertes y expansionistas, A y B, y dos relativamente débiles, C y D. En este modelo, el principio de Zona de Influencia regula las acciones de cada uno de ellos con los otros tres, ya sea en forma positiva o negativa. En el marco de un escenario internacional anárquico, con ausencia de un derecho internacional aceptado por todos y con mecanismos eficientes de represión para aquellos que lo vulneran, el principio de Zonas de Influencia puede ser, junto con el del Equilibrio del Poder, un mecanismo realista de mantener la paz, al menos entre los actores más poderosos. Todo ello se logra con una política de poder, de corte maquiavélico, en la cual el costo es la autonomía de los actores subordinados que quedan sometidos a un reparto en el cual no son consultados como actores ni contemplados en sus intereses.

El sistema ordenado a partir del criterio de Zonas de Influencia es una forma de vinculación dinámica. El actor subordinado puede ser un Estado independiente, que luego cae dentro de una Zona de Influencia, más tarde en colonia, o en territorio anexado. También puede darse el proceso inverso: una colonia puede cambiar de status, ganar en autonomía y quedar dentro de la Zona de Influencia de una nación más poderosa, para más tarde transformarse en actor independiente. Finalmente, un actor subordinado puede pasar a ser actor principal y viceversa.

Esta sería la definición de Zona del Influencia, según el uso que de ella hacen los principales referentes de la escuela realista de la Teoría de las Relaciones Internacionales, fundamentalmente Raymond Aron, en su obra Paz y Guerra entre las naciones. En esta obra de 1000 páginas, el autor utiliza el concepto en quince oportunidades, generando así un corpus teórico bastante amplio como para efectuar un análi- 
sis. Otros autores como Lenin (1917), Huntington (1972), Keohane y Nye (1977), Kenneth Waltz (1979), Gilpin (1987), Del Arenal (1990), Duroselle (1992) y Kennan (1996) mencionan ocasionalmente el concepto de Zona de Influencia, pero en menor medida que Aron, salvo quizá el caso de Lenin, que lo utiliza casi como sinónimo de "imperio colonial informal", para dar cuenta del sistema.internacional vigente en vísperas de la I Guerra Mundial. Mayor atención ha merecido este concepto en Seara Vázquez (1973) y Luard (1976), que ofrecen un análisis más amplio al respecto y lo utilizan como categoría más constantemente que los anteriores.

En general, las referencias de estos autores al concepto de Zonas de Influencia o Esferas de Influencia, es compatible con el uso del mismo que entrega Aron, quien ha logrado desarrollar más profundamente la idea. Precisamente por ello, el presente estudio se va a concentrar en el corpus que ofrece Aron, con el objetivo de iniciar un debate que aporte a la interpretación de las relaciones internacionales en el Cono Sur a partir de la detección de regularidades, sobre la base de una propuesta teórica coherente y resignificada.

\section{a. Zonas de Influencia y Grandes Potencias: el planteo teórico}

En la Teoría de las Relaciones Internacionales, disciplina desarrollada fundamentalmente en y para las grandes potencias, la capacidad de acción del país sobre su respectiva "Zona de Influencia" es compleja, profunda y de largo alcance. El concepto su utiliza para explicar el comportamiento de Estados con gran capacidad militar, política y económica, y cuya acción externa guarda proporción con esta capacidad. El análisis de la política exterior de estos países, suele incluir un espacio importante para evaluar su papel como imperios, es decir, sus sistemas de colonias y satélites. Y dentro de este contexto, se circunscribe el concepto de Zona de Influencia. En otras palabras, el sistema de "Zona de Influencia", junto con el de "Colonias" y "Protectorado", es una de las formas de dominación que las potencias europeas ejercieron sobre terceros países.'

De todos modos, existen diferencias entre "Zona de Influencia" y "Colonia" o "Protectorado". Una colonia carece de soberanía política. En cambio, un país incluido dentro de la Zona de Influencia de otro, puede ser formalmente independiente, gozar de sus propias instituciones políticas y de su integridad territorial. Tiene su bandera y su gobierno.

\footnotetext{
${ }^{1}$ Raymond, Aron. "Paz y Guerra entre las Naciones", Madrid, Revista de Occidente, 1963, págs. 329-330.
} 
Por ejemplo, en el siglo XIX y parte del XX, EE.UU. promovió una política de "puertas abiertas" en China, mediante la cual se procuraba preservar la integridad territorial de este país, a la vez que se admitía la posibilidad de la distribución de Zonas de Influencia de la misma entre las grandes potencias. ${ }^{2}$ Dentro de este enfoque tenemos algunos matices, que llevan a distinguir entre Zona de Influencia y Posesión Territorial: en la competencia entre dos Grandes Potencias, puede suceder que una de ellas "desea conquistar una posición que pertenece a la zona de influencia pero no al territorio del otro". 3

En la forma de interpretar el escenario internacional, Aron considera que las Grandes Potencias tienen por un lado sus "Territorios", sobre los cuales flamea su bandera e imperan sus leyes, y por otro sus "Esferas de Influencia", en donde su presencia política directa no es tan fuerte, pero sus derechos de acción tácitamente reconocidos son considerables. Es decir, también tendría un sentido político de subordinación la Zona de Influencia, aunque sería menos formal que en el Territorio.

En las grandes potencias, se distingue con claridad la predominancia de lo económico por sobre lo político. La distinción entre colonia y Zona de Influencia puede encontrarse en el tipo de lazo con la metrópoli, fundamentalmente entre la predominancia de lo político o lo económico respectivamente. Según los marxistas, las potencias europeas apuntaban a ensanchar sus colonias, para utilizar el control político como medio para ejercer mayor influencia económica. No obstante, Aron y otros teóricos detectan que también se ha producido el fenómeno inverso. Por ejemplo Gran Bretaña realizó fuertes inversiones de capitales en países que formalmente eran soberanos, como Argentina y Chile. En cambio, muchas colonias africanas de Francia y Gran Bretaña, a pesar de estar políticamente subordinadas a los gobiernos de esas potencias, no recibieron inversiones significativas. Por lo tanto, las colonias significaron una sujeción necesariamente política a la metrópoli, y alternativamente económica. En cambio, la Zona de Influencia sería lo opuesto: un país puede preservar su integridad territorial y sus instituciones políticas propias, pero se encuentra sujeto económicamente a una Gran Potencia. Aron ilustra estas ideas en los siguientes términos:

${ }^{2}$ El principio de la puerta abierta estaba destinado a preservar la independencia y la integridad territoriaj de China, objetivo éste que cra considerado como conforme al interés nacional y à ideal de los Estados Unidos. Pero la dificuitad no venía solamente de las ambiciones imperialistas de las potencias curopcas, sino también de la desintegración del antiguo régimen chino y de la ausencia de un gobierno central en Pekín, capaz de hacerse obedecer por todas las provincias y respetar por los estados extranjeros. Mientras una nueva dinastía no hubiese recibido un indiscutible mandato del cielo, las ingerencias europeas, con vistas a obtener privilegios o zonas de infiuencia, tenían que vencer fácilmente el obstáculo del "principio de la puerta abierta". Ibídem, pág. 677.

3 Ibídem, pág. 514. 
"La enormidad de los capitales invertidos por los europeos en territorios en que no ejercían la soberanía, la mediocridad de las sumas invertidas precisamente en aquellos lugares en que sí ejercían su soberanía, pone de relieve la relativa independencia de los dos movimientos: uno el de capitales; otro, el de soldados. Dejando de lado a Francia, cuyas conquistas en Africa del Norte fueron largas, lentas y costosas, las tomas de posesión por los países de Europa tenían lugar en aquellos sitios en los que no se exigían grandes esfuerzos. Los europeos no garantizaban sus inversiones más importantes con la soberanía política; se apoderaban de países débiles y anárquicos, ya para restablecer en ellos condiciones de intercambio beneficiosas, ya para adquirir condiciones estratégicas o para redondear y proteger territorios ya anexionados o ya, en fin, para contribuir a su gloria.

¿Podríamos decir, como sugiere en varios lugares Lenin, que las distintas maneras -zona de influencia, protectorado, colonia- en que se ejercía la dominación europea tienen poca importancia y que no son más que expresiones de un mismo hecho profundo: la dominación de Europa? Esta respuesta equivale a reconocer la distinción entre el movimiento económico y el movimiento político". ${ }^{4}$

Los lazos económicos entre la Gran Potencia y su satélite, aparecen como un punto clave para definir si éste se encuentra o no dentro de la Zona de Influencia de aquella. En este sentido, Aron plantea el caso de las relaciones entre la URSS con Siria y Afganistán, con un ejemplo claro y útil:

"La ayuda económica exclusiva no constituye un medio eficaz de asegurarse la fidelidad de un Pequeño, salvo a condición de que la ayuda represente una fracción importante de la renta nacional del país asistido. Esta condición se ha visto cumplida en dos casos: Afganistán y Siria. Los 115 millones de dólares adelantados (por la URSS) al primero equivalían al 23\% de la renta nacional de 500 millones de dólares; los 184 millones de dólares prestados a Siria equivalían al $46 \%$ de una renta nacional estimada en 400 millones. En este caso, la dependencia económica y política corre el riesgo de abrir el camino a una sovietización.

${ }^{4}$ Ibídem, págs. 329-330. 
En el momento de la creación de la República Arabe Unida, Siria estaba en trance de verse conquistada desde el interior por el partido comunista. Puede ser que Afganistán pertenezca ya a la esfera de influencia soviética aunque nada sea definitiva mientras los gobernantes del país no hayan perdido la capacidad de poder romper con su "bienhechor" y de volverse hacia el otro Grande."

Se destaca el predominio de lo económico por sobre lo político. Pero la relativa autonomía de lo político puede generar las condiciones para que se cuestionen esos lazos económicos, y por lo tanto, para que un territorio pueda salir de una Zona de Influencia en determinado momento. Es decir, existe cierta ambigüedad en el manejo del concepto. De todas maneras, este ejemplo de Aron revela que en su concepción, la Zona de Influencia guarda más relación con lo económico que con lo político. Recordemos que el texto está escrito en 1963, es decir, 17 años antes de la invasión de la URSS a Afganistán. Por lo tanto, según Aron, esa Zona de Influencia era más una subordinación económica que política.

Conforme a lo expuesto, se puede concluir que el concepto de Zona de Influencia ha sido diseñado por los teóricos para dar cuenta de una modalidad de política exterior de las Grandes Potencias, que son las que están efectivamente en condiciones de ejercer sobre la economía de un determinado país o territorio, una acción clara y franca sobre la base de las asimetrías en materia de desarrollo. Teniendo en cuenta que los países periféricos carecen por lo general de recursos para realizar una acción económica de estas características, podríamos concluir que desde este significado del término, habría muchas limitaciones para aplicar el concepto para las relaciones internacionales entre países periféricos. O bien, podemos señalar que para poder hacerlo, sería preciso realizar antes, una resignificación del concepto. De todas maneras, como se examina a continuación, desde otros puntos de vista, la categoría de Zona de Influencia sí puede resultar de utilidad para las relaciones entre países periféricos.

\section{b. Zona de Influencia: beneficiados y perjudicados}

El concepto de Zona de Influencia se utiliza también para dar cuenta de una forma de vinculación entre dos países relativamente grandes y expansionistas. En este sentido, toda la connotación negativa que surge

s Ibídem, pág. 607. 
del enfoque anterior (relación Gran Potencia-Satélite), se transforma en positiva al variarse el ángulo de la mirada (relación Potencia-Potencia). Los observadores señalan que una de las formas más adecuadas para preservar la paz, y las buenas relaciones entre dos países fuertes consiste justamente en el acuerdo tácito o explícito, de las Zonas de Influencia de cada uno. De esa manera se reduce la rivalidad, la virulencia y agresividad directa entre ambos competidores.

El antecedente más antiguo se remonta a las culturas clásicas. Inspirado en la obra de Tucídides, Aron detecta la aplicación del criterio de Zonas de Influencia en las relaciones entre las polis griegas. En este sistema, Esparta y Atenas cumplían el papel Potencias (A y B), mientras que las demás ciudades-estado serían los Satélites (C y D). Aron señala que mientras A y B estuvieron de acuerdo en la Zona de Influencia de cada uno (C y D respectivamente), se mantuvo la paz en la región. Pero cuando la línea se comenzó a alterar, cuando A inició acciones sobre D y B sobre C, se violó la regla de oro que sustentaba la paz y entonces se desencadenó la Guerra del Peloponeso:

"El equilibrio entre los dos campos se verá así, afectado por la conducta de numerosas unidades pequeñas. A falta de un 'tercer hombre', árbitro o ayuda, los dos Grandes están perpetuamente enfrentados, directamente o por personas interpuestas. Para entenderse les haría falta trazar una línea de demarcación y distribuirse las zonas de influencia decretando la prohibición de la disidencia: el cliente de uno de ellos no tendría derecho a pasarse al otro campo y cada uno se obligaría a no incitar a la disidencia a los aliados del otro. Reglas de este tipo, más o menos precisas, parece que existieron en Grecia en el transcurso del período precedente a la guerra del Peloponeso. Era difícil para las dos ciudades dueñas de la situación, respetar estas reglas y más difícil aún imponer su respeto a sus aliados respectivos". 6

Es preciso destacar que en este texto, como en la mayoría de los casos de relación entre países fuertes, el uso del concepto de Zona de Influencia va unido al de Equilibrio de Poder, que tenemos que reservar para desarrollarlo en otra parte. Porque se trata en el fondo de dos caras de la misma moneda. Además, cada época interpreta la historia con sus propias preguntas. En tiempos del sistema europeo (1648-1914), los es-

${ }^{6}$ Ibidem, pág. 180. 
tadistas se inspiraban en la teoría del Equilibrio de Poder, e interpretaban la obra de Tucídides fundamentalmente desde este enfoque: concebían a la Grecia Antigua como un modelo de sistema multipolar. En cambio Aron, al escribir en plena Guerra Fría, interpreta ese mismo escenario como un modelo de sistema bipolar. Aron prioriza una lectura de la Guerra del Peloponeso con mayor énfasis en las Zonas de Influencia, que era el sistema que él consideraba más adecuado para evitar la guerra termonuclear. Citando el caso de Grecia, Aron interpreta que para que se mantenga el equilibrio, es indispensable aflojar las tensiones, incrementar las garantías entre los dos estados competidores y ensanchar la base de estabilidad. Para ello sirve justamente, la definición de las Zonas de Influencia.

En los siglos XVI, XVII, XVIII y XIX, este sistema permitió relaciones más o menos pacíficas entre España y Portugal primero, e Inglaterra y Francia después. Hubo enfrentamientos entre ellos, pero fueron amortiguados sensiblemente por los acuerdos alcanzados con vistas a definir las Zonas de Influencia de cada uno, es decir, los territorios en los cuales podían expandirse y ejercer su acción política y económica. A veces esta acción iba acompañada por el control soberano del territorio de cada uno (España y Portugal en América Latina y Africa). En otros casos se optó por preservar la integridad territorial, pero abriendo espacios comerciales (Francia e Inglaterra en China).

Con el proceso de expansión del capitalismo, en el siglo XIX, la situación se complicó. Se hizo cada vez más difícil a las Grandes Potencias mantener los acuerdos sobre colonias y Zonas de Influencia. Esta fue la causa de la I Guerra Mundial, según Lenin (1917). Aron cuestiona esta interpretación, pues considera arbitraria la "teoría que Lenin quiso extraer de los hechos recogidos por Hobson, teoría que se resume en tres proposiciones: la exportación de capitales era inevitable; la toma de posesión o la creación de zonas de influencia era necesaria y la distribución pacífica del planeta, imposible."7 Igual que los liberales, Aron cuestiona la tesis marxista según la cual, la I Guerra Mundial fue el resultado inevitable de la expansión del capitalismo al alcanzar el nivel de imperialismo. Según Aron, el capitalismo no tiende necesariamente a generar colonias y Zonas de Influencia. Y aún en tal caso, las Zonas de Influencia pueden ser compatibles con un sistema de paz y equilibrio entre las Grandes Potencias. En vez de ser causa de la guerra, para Aron el principio de Zonas de Influencia puede ser funcional a la paz:

${ }^{7}$ Ibídem, pág. 328. 
"La tendencia de la economía capitalista, es decir, progresiva e individual, a extenderse a través del mundo no es puesta en duda. Todas las escuelas la admiten. Lo que la teoría tendría que demostrar es que la teoría capitalista no puede sobrevivir sin territorios todavía no capitalistas o, de otra forma, que esté condena$\mathrm{da}$, por sus contradicciones internas, al reparto del mundo en imperios coloniales y esferas de influencia, y que este reparto no pueda ser pacífico". 8

En este texto, Aron apela al estilo francés de negar lo contrario de lo que quiere afirmar. Es como decir "no está mal" en vez de decir "está bien", muy propio de los franceses. Pero en otros textos avanza con la idea, y la desarrolla en forma más positiva y clara, como veremos más adelante. Lo importante es que mientras los marxistas responsabilizaron al capitalismo como causa estructural e inevitable de la I Guerra Mundial, Aron estima que por el contrario, la expansión del capitalismo es compatible con la paz, siempre y cuando, las Grandes Potencias lleguen a un acuerdo sobre el alcance de las respectivas Zonas de Influencia. Aron admite que, si el sistema internacional es anárquico, las Grandes Potencias tienden a expandirse. A ese hecho de la realidad, Aron trata de proponerse las reglas para mantener la paz sin alterar la estructura socioeconómica vigente (el capitalismo). Es decir, Aron plantea el problema del carácter agresivo de las Grandes Potencias, y lo considera inevitable. Lo importante para él es reconocer esta realidad y desde allí formular una propuesta realista que evite el choque entre ellas.

Después de las guerras mundiales, los objetivos de dominación colonial entraron en decadencia. Las Grandes Potencias modificaron sus estrategias, y optaron por desembarazarse de las colonias que generaban altos costos. En su lugar, priorizaron los lazos de tipo económico con países soberanos, al menos formalmente. Esta tendencia se profundizó a partir de 1945 y puede decirse que la teoría de las Zonas de Influencia fue la principal herramienta empleada en las relaciones entre EE.UU. y la URSS para evitar un conflicto abierto entre ambas a lo largo de toda la Guerra Fría (1945-1989). Para Aron, así como el sistema internacional previo a 1914 estuvo conformado fundamentalmente por las Grandes Potencias y sus colonias, durante la Guerra Fría se avanza hacia un nuevo modelo con los dos Grandes y sus respectivas Zonas de Influencia. Aron introduce el concepto en los siguientes términos:

Blbidem, pág. 324. 
"La constitución de una zona de influencia soviética en el Este europeo provocó un reagrupamiento en el Oeste, el cual provocó una réplica bajo forma de estrechamiento de lazos entre las democracias populares y la Unión Soviética. La dialéctica de los bloques es, en sí, clásica y conforme a la lógica previsible de un equilibrio bipolar". ${ }^{9}$

Una vez definidos los dos bloques, para Aron, toda la estrategia de la política mundial, o bien, la clave del mantenimiento de la paz o el desencadenamiento de la guerra entre las dos Superpotencias, pasaba por la capacidad de construir dos Zonas de Influencia claras, donde cada uno tuviera la seguridad de poder actuar con tranquilidad, sin la ingerencia del otro. Pero esta propuesta se presentaba llena de dificultades y muy difícil de realizar.

"No habría ya apaciguamiento, en tanto que subsistan las tres causas principales de lo que hemos acordado llamar guerra fría: partición de Europa, carrera de armamentos, destino del tercer mundo. Ahora bien, estas tres causas constituyen el efecto más de lo que son los dos Grandes o los dos bandos, que de lo que hacen. El apaciguamiento exigiría una delimitación aceptada, de las zonas de influencia, lo que es incompatible con la pretensión universalista de cada una de las dos ideologías. El bloque socialista, por su mismo ser y fuera de toda acción subversiva, ofrece un modelo de desarrollo al tercer mundo. Occidente no puede dejar de temer la difusión del ejemplo soviético, puesto que los convertidos se transforman, a su vez, automáticamente en enemigos". ${ }^{10}$

La tesis central de Aron, es la forma de apelar al sistema de Zonas de Influencia como único mecanismo para mantener la paz y evitar la guerra en la era termonuclear. Pero por la naturaleza misma de las dos superpotencias, fundamentalmente por sus diferencias ideológicas, era prácticamente imposible obtener de cada uno, el compromiso de respetar la Zona de Influencia del otro.

"Cada bloque quiere levantar a las masas contra el régimen establecido en el bloque enemigo. Los Estados democráticos y los 
Estados soviéticos no pueden siquiera ponerse de acuerdo, igual que los príncipes protestantes y católicos, para delimitar sus zonas respectivas de influencia y para mantener la paz, renunciando a convertir en súbditos del otro lado de la línea de demarcación. En ausencia de una voluntad común de estabilidad, el esfuerzo constante de persuasión y de subversión surge de la heterogeneidad del sistema."

Para evaluar las condiciones para la paz, vigentes en la década de 1960, Aron se remonta al sistema previo a 1914 y al de los antiguos griegos. Sólo a partir de un entendimiento alrededor de las Zonas de Influencia es posible mantener el equilibrio y amortiguar el conflicto de intereses entre las Grandes Potencias.

\section{c. Beneficiados y perjudicados en el sistema de Zonas de Influencia}

El acuerdo en torno a Zonas de Influencia permite acotar la conflictividad entre países fuertes y competitivos, lo cual es positivo de cara a las relaciones bilaterales. Pero esto tiene un reverso claro: puede resultar muy perjudicial para los países relativamente menos poderosos. Es una situación parecida a la de los mercados, cuando los dos oligopolios pactan sus segmentos para evitar la competencia: automáticamente, la calidad de los bienes y servicios empeora y suben los precios. Ello perjudica a los clientes y beneficia a las grandes empresas, pues bajan sus costos. Igual que los oligopolios empresarios, la definición de Zonas de Influencia puede alterar las relaciones entre los estados, pues acentúa las asimetrías e incrementa el poder del fuerte sobre el débil.

La aplicación del sistema de Zona de Influencia permite a las Grandes Potencias lograr grandes beneficios cuando entre ellas deciden la suerte de terceros. Estos no son consultados ni tenidos en cuenta. Sólo se atiende a los intereses de las Grandes Potencias. Aron incluye esta distribución de Zonas de Influencia entre Grandes Potencias, dentro de un fenómeno mayor, que abarcaba también el desgajamiento de provincias, anexiones y firma de tratados secretos. Señala que estos procesos caracterizaron a la política europea hasta 1914, y fueron llevados a cabo tanto por repúblicas y democracias como por monarquías y autocracias.

\footnotetext{
${ }^{11}$ Ibidem, pág. 603.
} 
Después de la II Guerra Mundial, la consolidación del sistema bipolar fue acompañada por un nuevo reparto de Zonas de Influencia. Ello sirvió para mejorar las relaciones entre EE.UU. y la URSS, terreno en el cual resultó de óptima utilidad, al evitar el enfrentamiento directo. Pero a la vez, la delimitación de las Zonas de Influencia perjudicó los intereses de los terceros países. Así lo estima Aron en el momento de dar cuenta de la frustrada rebelión de Hungría en 1956: Arón lo explica en los siguientes términos:

"Trasladémosnos, mentalmente, a la crisis húngara de octubre y noviembre de 1956. Le represión de la Revolución húngara no constituyó más que un trágico episodio de la diplomacia al interior del bloque soviético, puesto que los Estados Unidos no intervinieron. Pero si éstos hubieran adoptado algunas medidas con vistas a una posible intervención, los dirigentes de Moscú hubieran podido elegir entre una derrota de primera magnitud (eventualmente, la disociación del bloque soviético) o la guerra -o hubiesen temido verse forzados a hacer esa elección. En esta coyuntura, la distribución de los papeles era equívoca: desde el punto de vista moral y de la legalidad internacional, la Unión Soviética corría con el papel de agresor. Pero, desde el punto de vista de la política de poder, la intervención de los Estados Unidos en las relaciones entre un Grande y un Estado satélite hubiera podido ser considerada como agresiva. ¿Quién hubiera tenido que dar marcha atrás?"

"Hasta el momento los dos Grandes se han guardado cuidadosamente de correr riesgos inútiles. Los Estados Unidos abandonaron a los húngaros a su desgracia y a su opresor. Más de dos años han transcurrido desde que el Sr. Krutschev se 'comprometió' a modificar el estatuto de Berlín. De manera general, existen acuerdos implícitos entre los Dos respecto a los medios que es legítimo emplear en cada región y en cada tipo de coyuntura". ${ }^{12}$

El texto de Aron ejemplifica el carácter ambivalente que tiene el uso del método de las Zonas de Influencia, en la política internacional. Los países fuertes se benefician, pues mantienen entre ellos el acuerdo de

12 Ibidem, págs. 511-512. 
convivencia; pero los terceros países quedan desprovistos de la protección que explícita o implícitamente esperaban. Es por tanto un método reprobable en sí mismo, pero que en caso de no existir otra posibilidad, y teniendo en cuenta el carácter anárquico del sistema internacional, en caso de emergencia, los países expansionistas y agresivos pueden apelar a las Zonas de Influencia como último recurso. Y esto es válido tanto para Grandes Potencias, como para las relaciones entre países periféricos, pero expansionistas y agresivos. Estos procedimientos de política exterior de Grandes Potencias, que se ponían de acuerdo entre sí para decidir sobre terceros que no eran consultados, es calificado por Aron como "maquiavélicos". 13

El principio de Zona de Influencia está pensado fundamentalmente para beneficiar en el corto plazo a dos grandes que compiten por la hegemonía. Ello contribuyó a evitar la guerra caliente entre EE.UU. y la URSS. Pero a la vez, resulta perjudicial para los actores pequeños, como refleja el caso de Hungría. Inclusive en el largo plazo, también puede resultar perjudicial para los poderosos. Sobre todo porque terminada la Guerra Fría, EE.UU. se encontró ante serias dificultades para controlar una situación inestable y compleja, creada precisamente en los años de tensión.

\section{Las Zonas de Influencia en el escenario regional del Cono Sur}

Después de haber definido el concepto teórico de Zonas de Influencia, conviene examinar la realidad de la política internacional en el Cono Sur, para reinterpretar los hechos a la luz de estas herramientas. Vamos a examinar el funcionamiento de este principio como idea rectora de las relaciones internacionales en el escenario regional, particularmente entre Argentina, Chile, Bolivia y Perú. Fundamentalmente en tres momentos decisivos: guerra del Pacífico (1879-1884), carrera armamentista finisecular (1896-1902) y la crisis del Beagle (1977-1984). En estos tres casos vamos a examinar cómo aparecen intentos de enfrentar a Chile con Argentina, por motivos de competencia por territorios o Zonas de Influencia. Pero finalmente, ambos países priorizan el

\footnotetext{
13 "Antes de 1914, las políticas exteriores de los Estados europeos pertenecian todas a un mismo tipo. Las cancillerías de las democracias parlamentarias respondian a una misma filosofía de maquiavelismo civilizado que utilizaban los Estados dinásticos, Imperios de los Romanov, de los Hohenzollern o de los Habsburgo. Cualesquicra que scan las responsabilidades que se les atribuyan a unos y otros en el desencadenamiento de la guerra de 1914, me parece indiscutible que, en cuanto a estrategia y a táctica, las conductas diplomáticoestratégicas de las distintas unidades no eran diferentes en su naturaleza. Los tratados secretos concluidos por los aliados con Itaila (para obtener la intervención de ésta uitima) o entre la Rusia de los zares y la Repüblica francesa, en 1917, suponían anexiones, desgajamientos de provincias y distribuciones de ZONAS DE INFLUENCIA". Ibidem, pág. 357.
} 
entendimiento directo y bilateral, y dejan a los terceros abandonados a su suerte.

\section{a. Argentina y la Guerra del Pacífico}

El empleo de las Zonas de Influencia como herramienta útil para las relaciones bilaterales entre Argentina y Chile, tuvo su bautismo de fuego con motivo de la Guerra del Pacífico. Este conflicto surgió en la década de 1870 en torno a la explotación de las salitreras fundamentalmente en Antofagasta (provincia de Bolivia) y Tarapacá (provincia del Perú). Obreros y empresarios chilenos tenían intereses y fuerte presencia en esta rica zona, que generaba exportaciones por montos millonarios. A medida que la renta se incrementaba, el interés por el control del área de multiplicó y con ello la potencialidad del conflicto.

Lentamente se fueron afirmando los antagonistas, Chile por un lado, Bolivia y Perú por otro. A su vez, éstos establecieron y firmaron un pacto secreto en 1873, y operaron diplomáticamente para arrastrar a la Argentina. En Buenos Aires se generó una corriente de opinión muy poderosa que se inclinaba a favor de la causa de Bolivia y Perú. Incluso hubo señales precisas de algunos grupos de la clase dirigente argentina, que se manifestó a favor de estrechar lazos con ambos países. Incluso la Cámara de Diputados llegó a dar media sanción al proyecto de incorporación al Pacto Secreto. ${ }^{14}$

Cuando estalló la Guerra del Pacífico (1879), nadie sabía exactamente qué actitud iba a asumir la Argentina. La diplomacia de Bolivia y Perú trabajó muy activamente en Buenos Aires para realizar el cuadrillazo contra Chile. El tema generó fuertes polémicas en los medios de prensa. Pero finalmente, el Estado argentino resolvió afirmar su neutralidad. Prefirió consolidar otros objetivos (promoción de la inmigración, expansión del ferrocarril y la producción agropecuaria), y renunció a las propuestas de involucrarse en el conflicto del Pacífico. Tal como hicieron los EE.UU. en 1956 con los húngaros, la Argentina abandonó a bolivianos y peruanos a su suerte, su trágica suerte. A cambio, logró afirmar su política migratoria. Millones de inmigrantes europeos llegaron a tierras argentinas, lo cual le permitió incrementar rápidamente su población. Además, la red ferroviaria se expandió a toda velocidad. Millones de hectáreas se incorporaron a la producción agropecuaria.

\footnotetext{
${ }^{14}$ Enrique M. Barba, "La alianza secreta de 1873 entre Bolivia y Pení. Tentativa para obtener la anexión argentina". En: Revista de Historia de América, Instituto Panamericano de Geografía e Historia, México, $N^{\circ} 22$, diciembre de 1946, págs. 273-351.
} 


\section{b. Los Pactos de Mayo y la consolidación de las Zonas de Influencia}

La fulminante victoria de las fuerzas armadas chilenas en la guerra del Pacífico, causó un fuerte impacto en Buenos Aires. La asombrosa toma del Morro de Arica, la captura del Huáscar y la toma de Lima generaron una mezcla de admiración e inquietud en la elite rioplatense. Para algunos, Chile era una suerte de Prusia de Sudamérica. Otros temían que el país Trasandino fuera una suerte de Esparta contemporánea. En general predominaba la sensación que con la Guerra del Pacífico se había roto el Equilibrio de Poder en la región. Muchos militares y políticos argentinos se sintieron amenazados. ¿No podría Chile volver ese magnífico ejército contra la Argentina? Para hacer frente a esta situación, el gobierno argentino tomó varias medidas: inició contacto con los gobiernos de Bolivia y Perú, encargó buques de guerra a astilleros europeos, y envió espías a Chile para realizar un relevamiento directo de la situación. . $^{5}$

Del lado chileno la situación también era apremiante. Sobre todo porque a pesar de la rápida victoria militar, la Guerra del Pacífico se prolongó casi indefinidamente en el campo político y diplomático: las autoridades de Bolivia, Perú y Chile no lograban ponerse de acuerdo en las bases para firmar los tratados de paz. Esta situación se dilató por años, lustros y hasta décadas, con las consiguientes tensiones que ello implicaba.

El escenario regional era bastante complejo hacia fines del siglo XIX. Chile era el país más fuerte militarmente, pero tenía una debilidad diplomática al no poder liquidar la guerra en el campo diplomático. Argentina se hallaba en una situación tensa, pues percibía a Chile como amenaza. Y consideraba que la coyuntura le daba la posibilidad de un acercamiento estratégico con Perú y Bolivia para reconstruir el equilibrio regional. Estos estaban tan postrados, que rápidamente olvidaron el desplante que sufrieron durante la guerra, y volvieron a confiar en la Argentina. Sobre todo cuando ésta se embarcó en una carrera armamentista sin precedentes, centrada en la compra de acorazados y otros buques de guerra, que eran más bien de los estándares de las Grandes Potencias.

Los partidarios de una Argentina con un papel rector en América del Sur, también participaron en este debate. Alentados por la euforia de los

15 Este tema lo tratamos en nuestro artículo "Espía en Chile, general de brigada en la Argentina: el pensamiento de Juan Serrato. Aceptado para publicación en: Diplomacia, revista de la Academia Diplomática "Andrés Bello", Santiago de Chile. 
indicadores económicos, estos grupos resaltaban una suerte de destino manifiesto de la Argentina, que debía proyectarse tanto en el Atlántico como en el Pacífico. Reivindicaban por ello, que el país debía realizar su "destino americanista", y tomar ingerencia en los asuntos de la región, especialmente en solidaridad con Perú y Bolivia.

La tensión fue en aumento. Chile percibió que el entendimiento entre Argentina, Perú y Bolivia, podía entorpecer notablemente sus negociaciones de posguerra. Y que sólo podría liquidar el asunto, haciendo frente a la presión argentina. Por lo tanto, Chile también entró en la carrera armamentista y se lanzó al mercado a comprar buques de guerra. La tensión alcanzó niveles sin precedentes. En la Navidad de 1901, Argentina y Chile llegaron a tener las $6^{\mathrm{a}}$ y $7^{\mathrm{a}}$ flotas de guerra más poderosas del mundo. ${ }^{16}$ Todo parecía listo para el desencadenamiento de las hostilidades, Chile por un lado, Argentina, Bolivia y Perú por otro. Pero justo en ese momento vino a jugar su papel, una vez más, el principio de las Zonas de Influencia.

En aquellos agitados meses del verano 1901-1902, la clase dirigente argentina se lanzó a un fuerte debate. El sector nacionalista, liderado por Estanislao Zeballos y el diario La Prensa, aseguraban que Argentina tenía intereses en el Pacífico y debía acudir en apoyo de Bolivia y Perú, en el marco de una política "americanista". Pero este era un americanismo muy distinto del que se desarrolló en la región en la década de 1860, signado por el Congreso de Lima, la guerra con España y el bombardeo de Valparaíso. En ese momento, el americanismo se entendía como una solidaridad igualitaria entre las naciones americanas, para hacer frente a las amenazas imperialistas europeas. Argentina no participó oficialmente de ese movimiento. En cambio, décadas más tarde en este país floreció una corriente que reflotaba el concepto de "americanismo", pero con un significado totalmente opuesto: en lugar de referir a una alianza solidaria entre pares, se proponía definir una política exterior nacionalista, de alcance regional, en la cual la Argentina estaba llamada a cumplir un papel rector. Para los partidarios de esta corriente, renunciar a esos sueños expansionistas equivalía a renunciar a la política exterior. $Y$ "una de las notas más características de la política americanista era la apelación de la intervención activa en las cuestiones del Pacífico; más concretamente, el respaldo a los reclamos de Bolivia y Perú como forma de contener la expansión chilena y la ruptura de equilibrios de poder en la zona", ${ }^{17}$

\footnotetext{
${ }^{16}$ Mario Barros Van Buren. Historia diplomática de Chile. Santiago, Andrés Bello, 2 edición, 1990, pág. 568.

${ }^{17}$ José Paradiso, "El poder de la norma y la política del poder". En: Jalabe, Silvia Ruth (compiladora), $L a$ política exterior argentina y sus protagonistas (1880-1995). Butenos Aires, CARI, 1996, pág. 16.
} 
Por su parte, el grupo pacifista, conducido por Bartolomé Mitre y el diario La Nación, propiciaba darle continuidad a la estrategia de paz con Chile, para priorizar el desarrollo desde y hacia el Atlántico. Dentro de esta corriente, un papel destacado cupo a Carlos Pellegrini para quien:

"Nuestros intereses políticos y económicos no están en el Pacífico. Todo nuestro porvenir, todos nuestros intereses morales y materiales, todo nuestro engrandecimiento y progreso se relacionan sólo con los pueblos que baña el Atlántico. Para nuestra vida internacional el planeta está dividido en dos hemisferios este y oeste por un meridiano que pasa por la Cordillera de los Andes. Toda nuestra actuación política tiene que ejercitarse sobre el hemisferio oriental: de allí nos viene la luz y con ella el progreso y la grandeza futura". ${ }^{18}$

Las dos corrientes antagónicas libraron una intensa batalla en los medios de prensa y en los foros parlamentarios de Buenos Aires. Finalmente se impuso la segunda posición. Como resultado, Argentina firmó con Chile los Pactos de Mayo (1902). Se puso fin a la carrera armamentista, y se aliviaron las tensiones bilaterales con bastante rapidez. Argentina abandonó por segunda vez a Bolivia y Perú a su suerte. Chile quedó con las manos libres para imponer los tratados que convenía a sus intereses nacionales.

Como era de esperar, la firma de los Pactos de Mayo desató fuertes críticas contra los gobiemos, especialmente del lado argentino. El inefable Estanislao Zeballos lideró la andanada de censuras contra el acuerdo. En una de sus tantas declaraciones contrarias al mismo, Zeballos aseveró que:

"Los pactos son la obra de la improvisación y de la desobediencia del ministro argentino (José A. Terry), que capitulando sin condiciones ante las exigencias de esa República (Chile), se impuso al gobierno argentino por medio de empeños familiares, induciendo a suscribir los pactos". ${ }^{19}$

\footnotetext{
${ }^{18}$ Citado en: José Paradiso, op. cit., pág. 16.

${ }^{19}$ Citado en: Siegrist de Gentile. "Política exterior argentina durante la presidencia de Figucroa Alcorta (1906-1910) y el memorando secreto del doctor Estanislao S. Zcballos". En: Sicgrist de Gentile, Nora, Gibral de Blacha, Noemí y Brailovsky, Antonio Elio. Tres estudios argentinos. Bucnos Aires, Sudamericana, 1982, pág. 64.
} 
Las palabras de Zeballos eran coherentes con el discurso que este dirigente mantuvo con respecto a Chile durante medio siglo, a través de los distintos espacios políticos y periodísticos que ocupó en Buenos Aires. En cierta forma, Zeballos no dejó pasar una oportunidad para fustigar este acuerdo. En otro momento, aseguró que el acuerdo era en realidad el resultado de "la improvisación diplomática impuesta al general Roca por los banqueros de Londres, apoyados por la credulidad romántica del general Mitre". Esta línea interpretativa sería desarrollada por numerosos historiadores argentinos en los años posteriores. Así se reflejó por ejemplo en la Historia de la Argentina, de Ernesto Palacios, uno de los manuales más influyentes en el tercer cuarto del siglo XX en este país: ${ }^{20}$

"Si bien los pactos de mayo tuvieron la virtud de impedir una guerra para la que no había a la sazón motivo suficiente, no hay duda de que la extensión de los compromisos que por ellos adquirimos significaron una disminución de nuestra personalidad internacional, de acuerdo con la más genuina tradición del régimen. A cambio de una promesa condicionada de no expansión territorial (salvo "el cumplimiento de los tratados vigentes" que la implicaban, en Tacna y Arica), nosotros asegurábamos la no injerencia en los asuntos 'externos' de los vecinos, lo que nos colocaba al margen de la vida internacional, que supone en esa materia una vigilancia recíproca permanente".21

Más adelante el autor agregaba:

"Bajo Roca se consolida, en efecto, el consabido pacifismo del régimen. Su doctrinario más importante es Mitre (...) Como no se trata de ser fuertes, sino de ser 'civilizados', el predominio militar queda excluido como finalidad del gobierno, así como toda otra preocupación por el destino de las 'atrasadas' naciones del resto del Continente (...) Al leer su mensaje de 1903, el general Roca habría de afirmar, después de dar cuenta de la prosperidad renaciente, que carecíamos de problemas en el orden externo.

\footnotetext{
${ }^{2 n E s t a ~ o b r a ~ s u ~ p u b l i c o ́ ~ p o r ~ p r i m e r a ~ v e z ~ e n ~} 1954$ y pronto se convirtió en un éxito cditorial. Muy recomendada por docentes de nivel medio, terciario y universitario, en 1968 iba por la $5^{2}$ edición; en 1975 se efcetuaron las ediciones $8^{2}$ y $9^{2}$. Hacia 1979 ya iba por la edición $11^{2}$.

${ }^{21}$ Emesto Palacio. Historia de la Argentina 1515-1976. Buenos Aires, Abcledo Perrot, 11 edición, 1979, pág. 598 .
} 
La renuncia a la política internacional significaba la confesión del destino colonial que el régimen vigente nos deparaba".

En una línea cercana, otros dirigentes de aquella época también combatieron ardientemente los Pactos de Mayo. Entre ellos cabe citar a Indalecio Gómez, una de las figuras que los historiadores nacionalistas más han destacado entre la élite de aquellos años. En carta a Carlos Pellegrini, el citado autor advertía:

"Si la opinión estuviera tan enervada que consintiera en los pactos, no veo esperanza razonable de que tuviera energía para oponerse a errores menos trascendentales. Pero si, perseverando en su movimiento contra aquellos, persuadida como está de que son malos, se recibiese el agravio de su sanción definitiva, entonces sí que se levantará airada y que sabrá impedir que en adelante gobiernen al país hombres semejantes a los que ahora infligen tamaña injuria a la soberanía. Defender los pactos, tratar de persuadir a la opinión de que son buenos, no es otra cosa que conspirar contra el renacimiento que usted anhela".22

Estas palabras no constituyen un papel más dentro de la maraña de correspondencia política argentina. Ha sido muy ponderada por la tradición historiográfica argentina, en su vertiente nacionalista. Por ejemplo para el influyente ensayista Julio Irazusta, esta carta de Gómez tiene el valor de "la mejor reseña de nuestra deplorable histórica diplomática". ${ }^{23}$ En resumidas cuentas, lo importante es destacar que las afirmaciones de Zeballos, Gómez y su grupo, reflejaban las dificultades que tuvo el partido pacifista de la Argentina, para llevar adelante el Tratado de 1881 y los Pactos de Mayo de 1902.

Los sectores pacifistas de la Argentina, liderados por Mitre, Roca y Pellegrini, habían logrado neutralizar a los grupos belicistas. La política "americanista", es decir, expansionista hacia el Pacífico, quedó suprimida con los Pactos de Mayo de 1902. Triunfaba sobre ella el principio de Zonas de Influencia, por el cual la Argentina se reservaba el Atlántico, y reconocía a Chile su total hegemonía en el Pacífico. De esta manera se cerraba un ciclo de veinte años de tensiones, y se abría el camino para medio siglo de concordia entre Argentina y Chile. Se terminó la carrera

${ }^{22}$ Citado en Julio Irazusta. Balance de siglo y medio. Bucnos Aires, $3^{\circ}$ cdición, 1983, pág. 83.

${ }^{23} \mathrm{Ibidem}$, pág. 83. 
armamentista, desaparecieron los pleitos de frontera como temas prioritarios del escenario diplomático bilateral y se generaron las condiciones para otra forma de relación entre ambos países.

\section{c. Un principio rector puesto a prueba: la crisis del Beagle y la Guerra de las Malvinas}

El esquema de Zonas de Influencia como herramienta clave de la política regional, iniciado en 1879-1884, y profundizado en la crisis de 1896-1902, llegaría a su punto culminante en la crisis del Beagle, 19771984. Argentina y Chile tenían una cuestión de límites pendiente en la zona del Canal de Beagle. El tema fue trasladado a arbitraje internacional, en el marco de los acuerdos de 1902. El laudo resulto favorable a Chile. El gobierno argentino tenía que acatar ese fallo, pues el compromiso solemne asumido por esta país era que, fuere cual fuere el resultado, el laudo era obligatorio e inapelable. Pero en el momento de conocerse el fallo (1 de mayo de 1977), el estado argentino estaba en manos de un gobierno militar que había tomado el poder mediante un golpe de Estado. Este gobiemo resolvió rechazar unilateralmente el laudo arbitral. Esta actitud fue duramente cuestionada en Chile, donde se señaló que Argentina había violado el derecho internacional y el principio de pacta sunt servanda. Pronto se llegaría al borde de la guerra.

Entramos aquí en un punto especialmente delicado en la historia de las relaciones entre Argentina y Chile. Objetivamente hablando, el gobierno argentino, al rechazar el laudo, incurrió en una suerte de "política del deshonor nacional", al violar un tratado solemne, ratificado por el Congreso, cuyo respecto las partes dejaban confiados al honor nacional. ¿Es posible alguna explicación racional para esto? La forma más fácil de resolver el problema, parecería ser la de responsabilizar a los militares: esta conducta parece bastante coherente en gobierno de facto que toma el poder por un golpe de Estado. Si no respetaron la Constitución Nacional, ¿por qué habrían de respetar un Tratado Internacional? Si realizaron una feroz represión interna, causando entre 10.000 y 30.000 bajas en la población argentina, ¿por qué no realizarían una guerra externa, en la cual se produciría un número parecido de muertos? Evidentemente, esta explicación puede parecer bastante razonable. Pero históricamente es inexacta.

La posición del gobierno de facto argentino en el sentido de rechazar unilateralmente el laudo arbitral del Beagle, fue apoyada por la mayor parte de la clase dirigente argentina. Periodistas, universitarios, empresarios y dirigentes políticos, multiplicaron expresiones de solidaridad con 
los criterios de los militares argentinos. Hubo algunas voces disidentes, muy minoritarias. También existía un fuerte clima de represión en la Argentina, con muchos disidentes encarcelados o exilados, que no tuvieron oportunidad de expresarse. Pero aquellos que gozaban de cierta capacidad de movimiento, se manifestaron de acuerdo con el criterio de los militares. Ello requiere entonces alguna forma de explicación, más compleja que la anterior.

Hasta el momento, se han ensayado varias explicaciones para tratar de justificar la decisión del gobierno argentino. Algunos juristas han señalado que el laudo se excedió en la materia que le fue confiada. Se le pidió que se pronuncia por las causas $A, B$ y $C$. Pero en el Laudo se definió sobre A, B, C y D. Por lo tanto, al haberse excedido en los límites puestos por las partes, el laudo es nulo. Este razonamiento puede parecer lógico, pero tiene una falencia notable: si hay buena voluntad de las partes, lo que corresponde es acatar el fallo sobre A, B y C, y en todo caso, pedir que se realice un nuevo arbitraje específico para resolver la situación de D. Lejos de ello, la Argentina rechazó todo en bloque, cuestionó la figura misma del arbitraje, denunció al tribunal como parcial, estigmatizó el fallo como "inglés", cuando provenía de un jurado formado por especialistas de países y tres continentes distintos. Por ultimo, optó por cerrar los canales de diálogo, retirar embajadores y movilizar las fuerzas armadas hacia ha frontera con Chile.

Desde el punto de vista jurídico, la posición argentina era injustificable. Al menos, no presenta visos de razonabilidad. Pacta sunt servanda, es la voz que resuena para recordar a todos los que buscan justificar lo injustificable. Pacta sunt servanda, la piedra angular de todo el edificio del derecho de gentes, es aquella que rechazaron los juristas argentinos y $\sin$ la cual no se puede justificar nada desde el derecho. Agotada esta vía, la posición argentina trató de justificarse desde la Geopolítica. Influidos por esta disciplina, muchos teóricos militares y civiles enfatizaron que estratégicamente, la propuesta del laudo era inaceptable pues lesionaba los intereses vitales de la Nación. Ya no se busca una legitimidad jurídica, sino estratégica. Era otra racionalidad, más cerca de los maquiavélicos criterios de la escuela denominada "realista", que de los principios y valores defendidos por la escuela "idealista", inspirada en la utopía de la paz perpetua de Kant.

Los partidarios de la Geopolítica ejercieron una notable influencia en el medio. Destacaron por ejemplo, que la aceptación del laudo afectaría los derechos de Argentina sobre la Antártida. Pero fundamentalmente, per- 
mitía a Chile tener una ventana al Atlántico. Y esta imagen causó alarma en los distintos sectores de la clase dirigente argentina. Historiadores, ensayistas, periodistas y demás formadores de opinión, enfatizaron con notable fuerza este punto. "Argentina en el Atlántico, Chile en el Pacífico", se titulaba el libro de Campobassi, centrado justamente en este enfoque.

La racionalidad de este énfasis era bastante cuestionable. Desde el punto de vista del derecho, los tratados bilaterales dejaban claramente determinada la vigencia del principio bioceánico hasta el paralelo 52, es decir, en el continente. Pero eran ambiguos desde Tierra del Fuego hacia el sur. Además, en el siglo XIX, el principio bioceánico fue propuesto por Chile para evitar que la línea de más altas cumbres, en caso de torcer en algún punto hacia el Pacífico, dejara a la Argentina un acceso a ese oceano, que cortara la continuidad territorial de Chile. Esto era muy diferente a la eventual presencia del país vecino en una lejana isla, 2.000 kilómetros al sur de Santiago o Buenos Aires, en una zona de navegación dificultosa y donde la circulación por los estrechos ya estaba resuelta debidamente. Si a ello se suma que ninguna de las tres islas en disputa superaba los $100 \mathrm{~km}^{2}$ de superficie, ni presentaba indicios de poseer mayor valor económico, entonces entra en crisis la racionalidad de esta argumentación.

¿Dónde encontrar entonces, una interpretación racional de la fuerte reacción negativa que causó en la Argentina el resultado del arbitraje? Parece probable que más que el valor real de esas islas, lo decisivo fue lo que ellas representaban. "El laudo brinda a Chile una ventana al Atlántico", destacaban los diarios con titulares catástrofe. $Y$ a partir de ello se generaba la alarma, el miedo. Se auguraba el advenimiento de perjuicios inefables para la Argentina. Nadie podía definir muy bien por qué, pero en general, con argumentos débiles se convencía fácilmente a una opinión pública que estaba como culturalmente predispuesta para acatar los vaticinios de estos agoreros.

El consenso se construyó en forma rápida y fácil. Ni un abogado argentino, ni un profesor ni un político salió a la prensa para indicar que el laudo era obligatorio e inapelable, y por tanto que rechazarlo era mancillar el honor nacional. Y por el contrario, decenas, centenares de declaraciones públicas, de los distintos sectores de la elite nacional, se encolumnaron fácilmente en el discurso alarmista, a pesar de su falta de fundamento. Y en la Navidad de 1978, se había logrado crear el clima bélico. La clase dirigente argentina apoyaba la política exterior del gobierno en el sentido de transmitir a la población la idea de la presunta justicia del reclamo nacional. 
Si este consenso no se construyó sobre lo que las islas del Beagle eran, sino en lo que representaban, lo importante es distinguir qué representaban. $\mathrm{Y}$ en este terreno hay que destacar el valor histórico del sitio por haberse desarrollado allí algún hecho clave de la historia o la identidad nacional (como la legendaria batalla de Kosovo en la guerra de 1999). Tampoco fue el lugar de nacimiento de algún argentino importante, ni sitio donde se haya derramado sangre de mártires, como Laguna del Desierto para Chile (1965). Entonces, ¿por qué tanto impacto por ese territorio?

Una forma de explicarlo puede ser la profundidad con la cual el principio de las Zonas de Influencia, estaba arraigado en la cultura argentina. Importantes sectores de la clase dirigente, desde fines del siglo XIX hasta fines del XX, plantearon en reiteradas oportunidades, el cuestionamiento a la política argentina de abandonar el litoral Pacifico a Chile. Numerosos mapas se difundieron para sustentar esta teoría, conforme a la cual, en tiempos del Virreynato del Río de la Plata, los actuales norte y sur de Chile, estaban sujetos a la autoridad de Buenos Aires. $\mathrm{Y}$ que por el tratado de Uti Possidetis Iuris, de 1856, estos territorios tendrían que pertenecer a la Argentina. Pero se habían perdido por la presunta "actitud claudicante" de la diplomacia argentina, que contrastó con la "actitud expansionista" de la diplomacia chilena. Los defensores de esta línea argumental, señalaban que los Pactos de Mayo fueron una muestra clara de esta actitud decadente de la Argentina, que renunció de esta manera a su "destino americano". Para contrarrestar este cuestionamiento, el sector más liberal de la elite argentina reivindicó durante un siglo el principio de la división bioceánica, como llave maestra de una política exterior que permitió al paîs crecer, expandirse y desarrollarse. El principio bioceánico, que en el plano teórico se aproxima al de Zonas de Influencia, fue entonces elevado a un plano mítico, y situado en un lugar indiscutible, por encima de cualquier cuestionamiento.

El significado del Laudo de 1977 fue que por primera vez en la Historia, se cuestionaba lo sagrado, se ponía en tela de juicio el mito. Y como el mito escapa al análisis racional, cualquier argumento que se presentara en el mismo sentido del mito, resultaba fácilmente aceptable. Era muy fácil de comunicar. No había que convencer a nadie pues todos los argentinos (o al menos, buena parte de la clase dirigente) ya estaban convencidos. De esta manera, el principio que en cinco oportunidades había facilitado las relaciones entre Argentina y Chile, ahora generaba un problema que parecía imposible de superar. La dimensión de la crisis que se generó al ser cuestionado este mito, es un excelente indicador de la magnitud del mismo. 
El mito pasó a jugar el papel inverso que había tenido hasta entonces. Si en 1879 y 1902 sirvió para distanciar a Argentina de Bolivia y Perú, esta vez empujó al país hacia el lado contrario. El gobierno de facto argentino inició contactos con Bolivia y Perú. Se realizaron ostentosas demostraciones públicas de acercamiento entre las autoridades de Argentina y sus potenciales aliados, sobre todo con Bolivia. Rápidamente se creo un clima de alianza en contra de Chile. La prensa fue alimentando estos vientos de hostilidad. Un diario de Bolivia publicó un artículo de ficción, en el cual relataba una eventual guerra, en la cual la alianza de Bolivia, Argentina y Perú lograba derrotar a Chile. Este artículo causó fuerte impacto y fue reproducido en los países vecinos, lo cual multiplicó su potencialidad agresiva y tensionante. En el verano de 1978, el gobierno argentino formalizó el rechazo unilateral e insólito del Laudo. Casi simultáneamente, el gobierno de Bolivia cortó relaciones diplomáticas con Chile y retiró su embajador. Las fuerzas armadas chilenas se apuraron a diseñar un plan de defensa que contemplara la HV3 (Hipótesis Vecinal 3), que constistía en la guerra simultánea en tres frentes. En este contexto, las fuerzas armadas chilenas procedieron a instalar minas en las zonas de posible invasión terrestre, sobre todo en la frontera con Bolivia y Perú. Se instalaron entre 500.000 y 1.000 .000 de minas, entre antipersonales y antitanques. Como la tensión iba en aumento, Bolivia y Perú creyeron que por fin, había llegado el esperado momento de tomarse revancha de la Guerra del Pacífico. Sobre el filo de la Navidad de 1978, el decreto de declaración de guerra estaba sobre el despacho del dictador Jorge Rafael Videla, y los comandantes de las fuerzas armadas tenían ordenes de iniciar las acciones militares.

En ese momento clave, entraron en escena los poderes económicos y culturales. La potencia hegemónica del momento, EE.UU., efectuó gestiones y presionó a los gobiernos de Argentina y Chile para reiniciar el diálogo. La mediación del Vaticano facilitó esta propuesta, con una mediación papal. El gobierno argentino reconsideró su posición. Aceptó reanudar el diálogo con Chile, y finalmente, se inició la mediación. Cuando las tensiones todavía estaban en un nivel elevado, Argentina invadió las Malvinas y anunció que "este es el primer paso en la redención de los territorios australes argentinos". Como Argentina después de la caída de Lima, esta vez Chile se sintió amenazado, e inicio la alianza por detrás: de allí la aproximación y el entendimiento de Augusto Pinochet con Margaret Thatcher.

El principio de las Zonas de Influencia, que había entrado en crisis en 1977, fue vulnerado con mayor profundidad en la guerra de las Malvinas, en 1982. El apoyo de Chile a Gran Bretaña, revelado por Thatcher en 1999 
con motivo de la detención de Pinochet, significó el primer involucramiento -directo o indirecto-de uno de los dos países expansionistas del Cono Sur, en la Zona de Influencia de su vecino. Fue la primer ruptura de un principio rector que se mantuvo vigente durante más de 120 años para mantener la paz y las buenas relaciones entre ambos.

El problema es que, al no tener este principio rector como herramienta válida, ni Argentina ni Chile tenían otro camino para entenderse. El conflicto se superó por la acción de una Gran Potencia, en este caso, Gran Bretaña, apoyada por la OTAN, que derrotó militarmente a las fuerzas armadas argentinas. Lo mismo había sucedido en la crisis de 1977, cuando al entrar en crisis el principio rector de las Zonas de Influencia, Argentina y Chile necesitaron de una potencia superior para resolver el problema y superar la tensión, en este caso, EE.UU. y el Vaticano.

La guerra de las Malvinas modificó el cuadro político interno de Argentina, y también por ende, su política exterior. Los militares se replegaron a los cuarteles y devolvieron el poder a los civiles a través de las elecciones de octubre de 1983. El Tratado de 1984 dio por superada la cuestión del Beagle y abrió paso a una nueva era de entendimiento entre ambos países. El Tratado de 1991 y el Acta de San Luis, de 1996, fueron posibles por el nuevo escenario regional establecida a partir de las Malvinas.

Una vez más, Argentina y Chile se ponían de acuerdo entre ellos para resolver pacíficamente sus diferencias. Y una vez más, Argentina frustraba las expectativas de Bolivia y Perú. Las consecuencias fueron bastante negativas para estos dos países. Los campos minados no fueron removidos, debido a sus altos costos y quedaron como una amenaza latente. Las relaciones diplomáticas entre Bolivia y Chile, rotas en solidaridad boliviana con Argentina en el verano caliente de 1978, se mantuvieron así hasta el siglo siguiente. Y las relaciones culturales de Bolivia y Perú con Chile, quedaron afectadas por un buen tiempo, lo mismo que el comercio y otros aspectos.

\section{Conclusiones}

La política exterior de Argentina y Chile en sus relaciones bilaterales, ha tenido como principio rector fundamental, el respeto por las Zonas de Influencia: Argentina en el Atlántico y Chile en el Pacífico. Mientras este principio estuvo vigente, ambos países gozaron de buenas relaciones bilaterales, y pudieron realizar una fuerte expansión territorial y eco- 
nómica hacia el norte, el sur y sus respectivos litorales marítimos. Por el contrario, cuando este principio rector entró en crisis (1977-1984), ambos países quedaron como desorientados. Se quedaron sin reservas para resolver los problemas entre ellos en forma pacífica. Todo parecía conducir al camino de las armas, y esta alternativa sólo se superó por la acción de Grandes Potencias, primero EE.UU. (1978) y luego Gran Bretaña (1982). La crisis de 1977, generada justamente cuando se cuestionó el principio de las Zonas de Influencia, generó un impacto de tanta magnitud, que permitió revelar la importancia histórica de este principio en las relaciones bilaterales.

La larga vigencia del principio de Zonas de Influencia entre Argentina y Chile, resultó positivo para las relaciones bilaterales, si nos atenemos al enfoque de la teoría realista de las Relaciones Internacionales: evidentemente, este criterio resultaría una herramienta adecuada para alcanzar objetivos nacionales de expansión territorial y consolidación económica y política regional. Pero hay que advertir también que este principio resultaría nefasto para los terceros. Este entendimiento entre las dos potencias expansionistas del Sur de América, confundió a Bolivia y Perú, que tal vez confiando en el apoyo de Argentina, realizaron una diplomacia más agresiva hacia Chile, lo cual finalmente les resultaría fatal.

La evaluación del funcionamiento de este principio es relativa al enfoque desde donde se realice la medición. Si se consideran solo las relaciones bilaterales entre Chile y Argentina, puede decirse que este principio fue exitoso, al menos para los antiguos criterios del interés nacional. Pero si lo que se considera es la región, entonces el resultado de la evaluación es negativo, porque al alcanzarse el acuerdo de Zonas de Influencia, se facilitó la ruptura del Equilibrio del Poder en la región, lo cual llevó a guerras destructivas de notable magnitud.

Inclusive, a la luz del nuevo criterio de evaluación de las relaciones internacionales, sobre todo si se tiene en cuenta la teoría de la Interdependencia para superar los límites de la antigua teoría realista, podemos cuestionar la conveniencia del principio de las Zonas de Influencia para las relaciones bilaterales. Como hemos señalado antes, este principio rector logró que Argentina y Chile alcanzaran dos objetivos: mantener la paz entre ellos y expandirse en detrimento de terceros. Pero si complejizamos el análisis, podemos matizar este resultado. Porque si bien los dos objetivos anteriores fueron efectivamente alcanzados, también se produjeron efectos secundarios negativos perjudiciales tanto para Argentina como para Chile. Entre ellos podemos señalar los siguientes: 
En primer lugar, se afectó decisivamente el proceso de desarrollo económico de países vecinos, que hoy podrían ser socios comerciales dinamizadores de ambas economías. En su momento, Paraguay, Bolivia y Perú eran países relativamente pujantes con los cuales se podía pensar en un proceso importante de complementación económica, capaz de generar beneficios para ambas partes. Pero el daño que las guerras causaron en el corazón de la economía de esos países, les generó una postración de la cual todavía no han podido salir.

Por otra parte, el principio rector de Zonas de Influencia se elevó a categoría de mito y se hizo inmanejable, hasta volverse en contra de sus gestores; el carácter casi sagrado del principio bioceánico impidió al gobierno argentino aceptar el Laudo de 1977, y estuvo a punto de llevar a ambos países a la guerra en 1978 y 1982.

Este principio se transformó en un molde rígido, muy poco flexible y por tanto, poco apto para el desarrollo de una política exterior acorde a los cambios de escenario; en la crisis de 1977 a 1982, se desnudó la falencia del servicio exterior de ambos países, que al perder la única herramienta que sabían usar para el manejo de las relaciones bilaterales, sólo atinaron, impotentes, a resolver las diferencias por las armas: y fue necesaria la ingerencia de Grandes Potencias (EE.UU. en 1978 y Gran Bretaña en 1982) para resolver el pleito.

La rigidez de este principio generó, indirectamente, un conjunto de ideas que tomarían la forma de un nuevo ideario, autónomo con respecto al anterior pero derivado de él: la oposición al acceso del país trasandino al litoral marítimo opuesto; tanto en Argentina como en Chile se desarrolló la cultura de la desconfianza hacia toda iniciativa que facilitara el acceso del vecino al océano propio. Esto complicó todas las gestiones e iniciativas tendientes a construir corredores bioceánicos. La sola presencia de chilenos en el Atlántico o de argentinos en el Pacífico, sería motivo de preocupación y hasta de alarma para algunos sectores. Ello podría generar competencia para los propios productos en los mercados. O bien, producir otros problemas, cuya magnitud sería difícil de prever. Estas ideas se difundieron en las burocracias estatales, en los cuadros militares, en las cámaras empresarias y hasta en amplias capas medias y populares. El resultado está a la vista: nunca se construyó el ferrocarril paralelo a los Andes, ideado por Olascoaga (1901), ni el ferrocarril trasandino por el sur. Nunca se termina de pavimentar la Ruta Nacional 40, que es la paralela a la Ruta 5 chilena y su complemento natural; de los 50 pasos cordilleranos, apenas uno se ha aprovechado para construir una carretera internacional apta para el transporte comercial de carga pesada. 
Bibliografía

Pablo Lacoste

El concepto de Zonas de Influencia y su aplicación en las relaciones entre Argentina y Chile

Aron, Raymond. Los últimos años del siglo. Buenos Aires, EMECE, 1985.

Aron, Raymond. Paz y guerra entre las naciones. Madrid, Revista de Occidente, 1963.

Barba, Enrique M. "La alianza secreta de 1873 entre Bolivia y Perú. Tentativa para obtener la anexión argentina". En: Revista de Historia de América, Instituto Panamericano de Geografía e Historia, México, $\mathrm{N}^{\circ} 22$, diciembre de 1946, págs. 273-351.

Canclini, Arnoldo. Piedrabuena, su tierra y su tiempo. Buenos Aires, EMECE, 1998.

Del Arenal, Celestino. Introducción a las relaciones internacionales. Madrid, Tecnos, 1990.

Duroselle, Jean Baptiste. Todo imperio perecerá. Teoria de las relaciones internacionales. México, FCE, 1998.

Gilpin, Robert. La economía politica de las Relaciones Internacionales. Buenos Aires, GEL, 1987.

Huntington, Samuel. El orden político en las sociedades en cambio. Barcelona, Paidos, 1972.

Kennan, George. Al final de un siglo. Reflexiones, 1982 1995. México, FCE, 1996.

Keohane, Robert y Nye, Joseph. Poder $e$ Interdependencia. La política mundial en transición. Buenos Aires, GEL, 1977.

Jalaba, Silvia Ruth (compiladora). La politica exterior argentina y sus protagonistas 1880-J995. Buenos Aires, CARI/GEL, 1996.

Lenin, V. I. El imperialismo, etapa superior del capitalismo, 1917.
Luard, Evan. Types of International Society, Nueva York/Londres, 1976.

Rojas Lagarde, Jorge Luis. Incidentes fronterizos con Chile durante la guerra con el indio. Buenos Aires, 1997.

Seara Vazquez, Modesto. "Zones of influence". The Year Book of World Affairs, vol. 27 (1973), págs. 301-315.

Waltz, Kenneth. Teoría de la Política Internacional. Buenos Aires, GEL, 1979. 